\title{
Assessment of Gilsonite and Trinidad Epuré natural asphalt- modified binders ability to relaxation at low temperature
}

\author{
Bilski Marcin ${ }^{1, *}$ and Stowik Mieczysław ${ }^{1}$ \\ ${ }^{1}$ Poznan University of Technology, Institute of Civil Engineering, Plac Marii Skłodowskiej-Curie 5, 60-965 Poznan, Poland
}

\begin{abstract}
The paper presents the results of the tests conducted on asphalt binders modified with additives of natural Gilsonite and Trinidad Epuré asphalts, as well as the 20/30, 35/50 and 50/70 penetration grade bitumens by use of an original observation method of the relaxation phenomenon in low temperature. In the tests the authors used a ductilometer equipped with a dynamometer and a bath filled up with a liquid with the temperature of $-16^{\circ} \mathrm{C}$. Relaxation of the asphalt binder was observed in the period of 20 minutes in the conditions of constant deformation of the sample caused by its prior extension with the constant speed of $1 \mathrm{~mm} / \mathrm{min}$. The value of the normal stress occurring in the asphalt binder is calculated on the basis of the measured value of the normal (tensile) force. It has been noted that asphalt binders with higher penetration values are characterised by a better relaxation ability at low temperature, that is relaxation takes place faster and has higher values of sample stress reduction in the domain of time, at constant strain. With approximate penetration values (the maximum penetration difference at $25^{\circ} \mathrm{C}$ amounting to $\pm 2 \mathrm{~mm} / 10$ ), modified binders comprising Gilsonite are characterised by better relaxation abilities in comparison to binders containing the Trinidad Epuré additive.
\end{abstract}

\section{Introduction}

The relaxation phenomenon occurs e.g. where a material is submitted to deformation (e.g. as a result of stretching), and stress is decreasing in time, at constant strain. The relaxation ability of asphalt binders at low temperature is favourable due to having a positive effect on the asphalt pavement's resistance to cracking. A cumulation of stress in asphalt binders may take place both as a result of thermal change (cooling of the pavement causes asphalt binders to contract), as well as traffic loads. Temperature is a factor determining the intensity of relaxation. In order to limit the negative influence of low temperature on the pavement condition, it is essential to choose an asphalt binder having in mind the specific course it is to be applied in, and the climatic zone for the pavement [1]. In terms of asphalt pavement's resistance to low-temperature cracking, it is a desired feature of the asphalt binder to be able of fast relaxation. Asphalt binders characterised by low relaxation ability are more susceptible to lowtemperature cracking, because they are submitted to thermally induced tensile stress.

An asphalt binder is a viscoelastic material, which means that its viscous part (linked to i.a. relaxation ability) is increased or decreased depending on temperature. At low temperature, soft asphalt binders (with high penetration at $25^{\circ} \mathrm{C}$ ) or binders containing modifiers e.g. in form of elastomers have a higher viscous part content compared with hard asphalt binders (with low penetration at $25^{\circ} \mathrm{C}$ ) or binders stiffened as the result of modifications with e.g. plastomers [2]. The higher viscous part content results in asphalt binders being less susceptible to low-temperature cracking, i.a. due to a higher and faster relaxation ability.

Modifying road bitumens with natural asphalt additives increases their stiffness, which, in consequence, may translate into a lower resistance of the modified binder to low-temperature cracking [3]. Currently, the bending beam rheometer (BBR) is an apparatus typically used to assess the stiffening of an asphalt binder sample at low temperature, based on the value of the stiffness modulus and the increase of the stiffness gradient (creep at static loading and recovery after unloading). A m-value (stiffness gradient) determined using BBR method is a parameter which can be used to assess the ability of bitumen to relaxation at low temperature [4].

The relaxation phenomena occurring in asphalt binders at low temperature is very well recognized $[5,6]$, but is a lack of standards or specifications pertaining to investigation of relaxation. For example, to assess the relaxation of asphalt binders at low temperatures, the authors of the paper [7] have used a dynamic shear rheometer (DSR). Using the DSR method the relaxation phenomena can be observed as a result of application of constant shear strain in relation to time. In the case of using the DSR method to assess the asphalt binder relaxation not occur a simple state of stress the authors of the paper have decided to introduce an original test method. Using a ductilometer to observe relaxation phaenomena it is possible to get a simple state of stress,

* Corresponding author: marcin.bilski@put.poznan.pl 
i.e. only tensile stress occurring. The results of that test method are allow to compare the properties of different asphalt binders in a simple way and are easy to mathematical modelling of the relaxation phenomena. Mathematical modelling is more difficult when using the DSR method, for example [8].

\section{Purpose of the study}

For the purpose of comparing the relaxation abilities of road bitumens and asphalt binders modified with Gilsonite and Trinidad Epuré natural asphalts, the authors introduced an original test method, discussed in detail in paper [9], which enables them to study the relaxation phenomenon of binders in the conditions of constant strain at low temperatures. The determination of natural asphalt-modified binders ability to relaxation at low temperature is particularly important because the application of natural asphalt causes a stiffening effect of the bitumen [3].

\section{Subject of the tests}

The three road binders used in the tests were 20/30, $35 / 50$ and $50 / 70$ penetration grade bitumens produced from Russian crude oil, and also natural asphalts: Gilsonite in powdered form and Trinidad Epuré in aggregate form of $0 / 8 \mathrm{~mm}$ graining. The content of the additive in the form of the natural asphalt in the road bitumens $35 / 50$ and 50/70 was established after having conducted a series of trial determination of penetration values at $25^{\circ} \mathrm{C}$. These were performed in a way to guarantee that upon modification road bitumens should become asphalt binders with approximate penetration values, that is, it has been assumed, that the difference between the determined penetration values will not be greater than $2 \mathrm{~mm} / 10$. The application of the percentage of the additive in relation to the modified asphalt binder's mass was $3 \%, 5 \%, 7 \%$ for Gilsonite, and $15 \%$, $25 \%, 35 \%$ for Trinidad Epuré. The authors adopted the following method of marking the attained asphalt binders: primarily with the type of road bitumen, secondly, with the type and content of the applied additive. Gilsonite was marked as GIL for short, and Trinidad Epuré as TE. For example, a 50/70 penetration grade bitumen with a $25 \%$ Trinidad Epuré additive would be $-50 / 70+25 \%$ TE. Basic properties of the studied asphalt binders can be seen in Table 1 .

Table 1. Basic properties of the asphalt binders studied in the paper.

\begin{tabular}{|c|c|c|}
\hline Asphalt binder & $\begin{array}{c}\text { Penetration } \\
\mathbf{a t ~}^{\circ}{ }^{\circ} \mathbf{C} \\
\mathbf{m m} / \mathbf{1 0}\end{array}$ & $\begin{array}{c}\text { Softening Point } \\
{ }^{\circ} \mathbf{C}\end{array}$ \\
\hline $20 / 30$ & $25.6 \pm 0.5$ & $63.6 \pm 0.2$ \\
\hline $35 / 50$ & $40.8 \pm 0.3$ & $55.9 \pm 0.5$ \\
\hline $35 / 50+3 \%$ GIL & $27.2 \pm 0.3$ & $61.1 \pm 0.2$ \\
\hline $35 / 50+5 \%$ GIL & $24.4 \pm 0.5$ & $62.9 \pm 0.3$ \\
\hline $35 / 50+7 \%$ GIL & $19.8 \pm 0.3$ & $65.3 \pm 0.2$ \\
\hline $35 / 50+15 \%$ TE & $28.6 \pm 0.7$ & $57.5 \pm 0.3$ \\
\hline
\end{tabular}

\begin{tabular}{|c|c|c|}
\hline $35 / 50+25 \% \mathrm{TE}$ & $24.8 \pm 0.3$ & $59.5 \pm 0.2$ \\
\hline $35 / 50+35 \% \mathrm{TE}$ & $19.2 \pm 0.5$ & $62.0 \pm 0.2$ \\
\hline $50 / 70$ & $55.9 \pm 0.7$ & $51.6 \pm 0.2$ \\
\hline $50 / 70+3 \%$ GIL & $38.6 \pm 0.3$ & $55.8 \pm 0.4$ \\
\hline $50 / 70+5 \%$ GIL & $32.6 \pm 0.4$ & $57.2 \pm 0.3$ \\
\hline $50 / 70+7 \%$ GIL & $26.6 \pm 0.7$ & $60.4 \pm 0.4$ \\
\hline $50 / 70+15 \%$ TE & $39.7 \pm 0.6$ & $53.3 \pm 0.3$ \\
\hline $50 / 70+25 \%$ TE & $32.0 \pm 0.6$ & $55.7 \pm 0.3$ \\
\hline $50 / 70+35 \%$ TE & $25.8 \pm 0.6$ & $58.6 \pm 0.4$ \\
\hline
\end{tabular}

The natural Gilsonite asphalt is extracted from deposits in North-East part of the Utah state (USA). This material is a natural mixture of (per product mass) coal $85 \%$, hydrogen $-10 \%$, nitrogen $-3 \%$ and oxygen, sulphur and other components in the amount of about $2 \%$. Gilsonite is a material belonging to the group of asphaltites, resembling bituminous coal in appearance $[10,11]$.

Trinidad Epuré is a natural asphalt loosened from the surface of the Pitch Lake in the vicinity of the town of La Brea in the island of Trinidad, and submitted to the refinery process. The process consists in i.a. heating the acquired material in order to soften it, evaporate free water and chemical compounds dissolved in it, as well as to separate mineral and organic impurities, e.g. in the form of stones or wood $[12,13]$.

\section{Methodology of the studies}

The test method designed by the authors was used to analyse the relaxation phenomenon in the conditions of constant strain of asphalt binder samples at low temperature due to the high precision of the measurements. The approximate value of the tensile force remains with $95 \%$ probability within the range \pm 1 $\mathrm{N}$ [9]. A schematic of the test can be seen in Figure 1. The asphalt sample is extended until reaching a specific value of the tensile force (in time from $t_{0}$ to $t_{1}$ - linear increase of stress and strain in time is assumed), and then is kept in the conditions of constant deformation, so that relaxation can be observed (time from $t_{1}$ to $t_{2}-$ stress values are reduced in time at constant stress) until the end of the test $\left(t_{2}\right)$

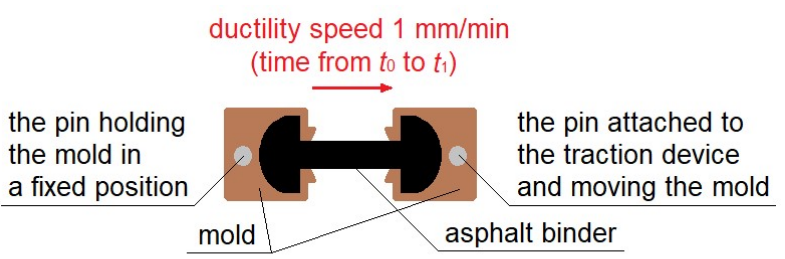

end of the ductility $\left(t_{1}\right)$ when the tensile force reach $50 \mathrm{~N}$
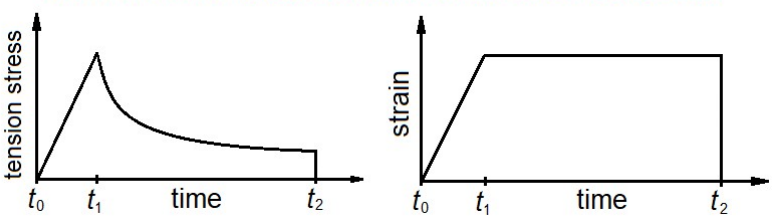

Fig. 1. A diagram of relaxation tests in a ductilometer. 
While applying this method for assessment of relaxation at constant deformation at $(-16 \pm 0.2)^{\circ} \mathrm{C}$ in road bitumens and natural asphalt-modified binders, the authors used a ductilometer consisting of: a liquid bath with a thermostat, an extension mechanism, a dynamometer, as well as brass moulds used in the modified asphalt binders extension tests according to EN 13589:2008 Bitumen and bituminous binders Determination of the tensile properties of modified bitumen by the force ductility method. The ductilometer bath was equipped with an extra cooling system, which made it possible to sustain the required temperature of $-20^{\circ} \mathrm{C}$ during the test. The selected test temperature was $-16^{\circ} \mathrm{C}$, allowing for an attempt to relate the achieved results of asphalt binders studied in the paper to the tests conducted at the same temperature by use of a bending beam rheometer (BBR).

The procedure of preparing the samples consisted in pouring a hot asphalt binder into brass moulds (in compliance with EN 13589) placed on laboratory scale with the reading accuracy of $0.01 \mathrm{~g}$. The binder mass placed in a single form was $(13.75 \pm 0.25) \mathrm{g}$. The next step was placing a silicone pad on the brass form moulded with asphalt binder; the pad was pressed with a steel circle-shaped stamp of the diameter of $60 \mathrm{~mm}$ in order to achieve a perfectly equal surface in the middle part of the sample. It was subsequently left for cooling down for the period of $(60 \pm 1)$ minutes. The next stage was to cool the samples in the ductilometer bath for the period of $(30 \pm 1)$ minutes. Next, the samples were submitted to stretching with the speed of $1 \mathrm{~mm} / \mathrm{min}$ until reaching the tensile force $50 \mathrm{~N}$ (ending point of the stretching procedure), and the values of the tensile force in the conditions of constant strain during the period of
20 minutes were noted. There were four repetitions for each of the tested asphalt binders. The value of $50 \mathrm{~N}$ of tensile force was determined experimentally, so as to obtain the possibility of comparing the different asphalt binders while keeping the minimal deformation (strain) in the sample, which not exceed the value of $1 \%$ [9]. The maximum extension of the samples with a length $30 \mathrm{~mm}$ during the test was $0.25 \mathrm{~mm}$. By using the values of the tensile force determined in the course of the experiment, it was possible to calculate the tensile stress in the asphalt binders per Formula 1, assuming, due to a low sample deformation that the cross-section is invariable.

$$
\sigma=F \cdot A^{-1}
$$

where:

$\sigma$ - value of tensile stress, $\mathrm{Pa}$,

$F$ - value of tensile force, N,

$A$ - surface area of the cross-section of the sample, $10^{-4} \mathrm{~m}^{2}$ (a sample with a square section having the side length of $1 \mathrm{~cm})$.

\section{Test results}

Figures 2 and 4 show the results of determining the values of the tensile force in the function of time in the conditions of constant strain at $-16^{\circ} \mathrm{C}$ of chosen asphalt binder samples - comparable in terms of their penetration values at $25^{\circ} \mathrm{C}$ - the $20 / 30$ penetration grade road bitumen and modified asphalt binders $35 / 50+5 \%$ GIL and $35 / 50+25 \% \mathrm{TE}$, respectively.

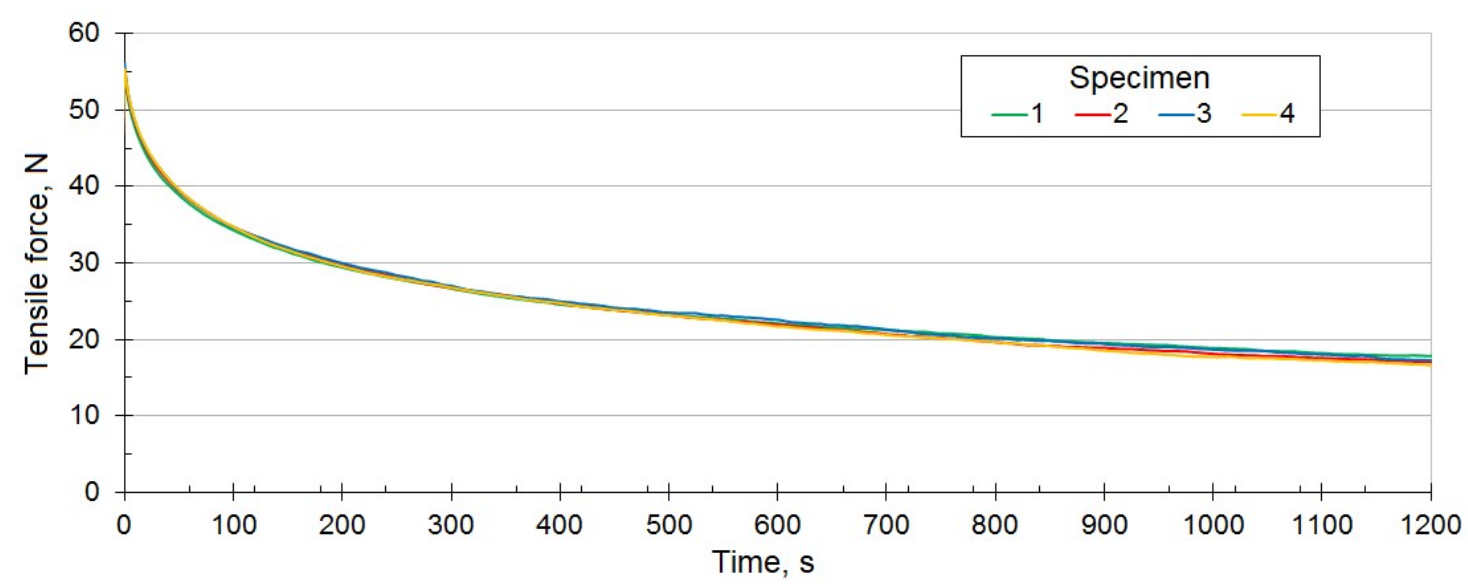

Fig. 2. The values of the tensile force in the domain of time in the conditions of constant strain in the case of 20/30 penetration grade road bitumen at $-16^{\circ} \mathrm{C}$. 


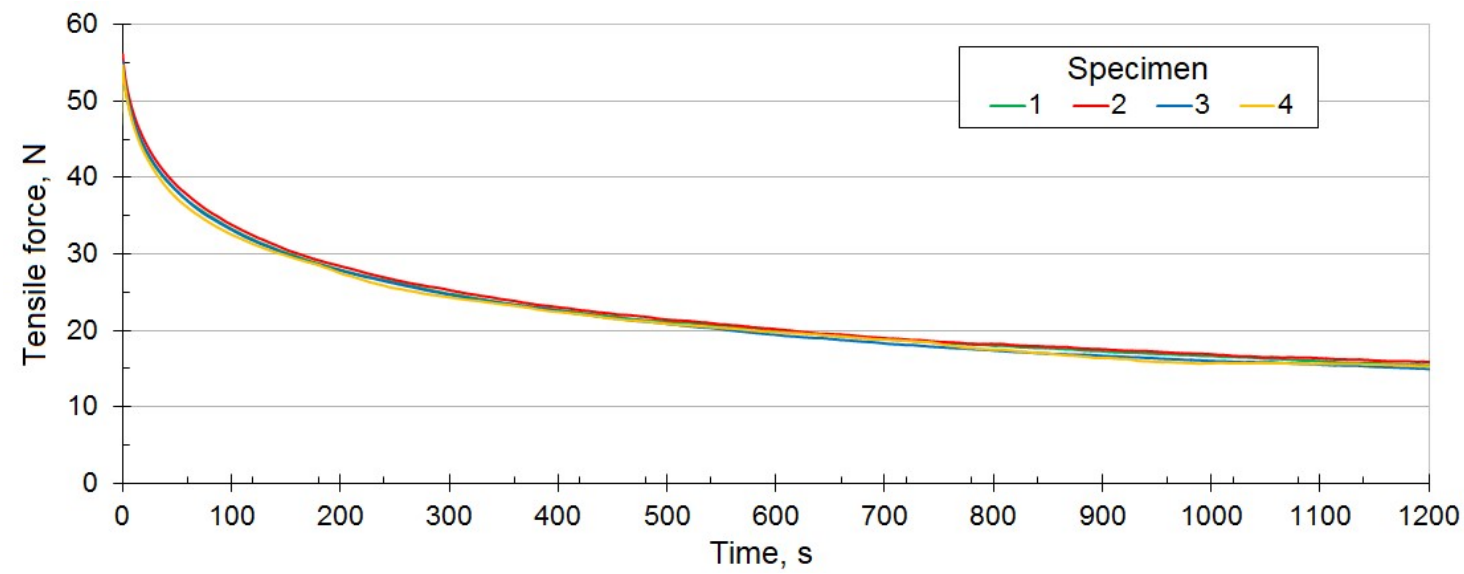

Fig. 3. The values of the tensile force in the domain of time in the conditions of constant strain in the case of modified asphalt binder $35 / 50+5 \% \mathrm{GIL}$ at $-16^{\circ} \mathrm{C}$.

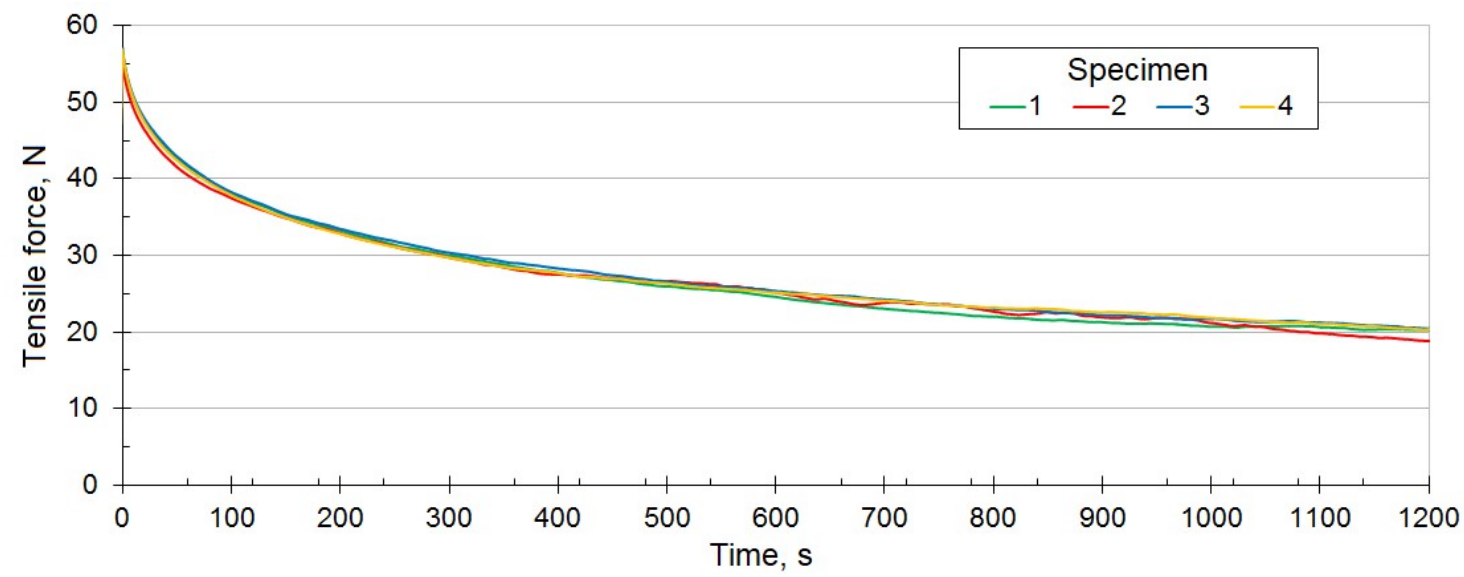

Fig. 4. The values of the tensile force in the domain of time in the conditions of constant strain in the case of modified asphalt binder $35 / 50+25 \% \mathrm{TE}$ at $-16^{\circ} \mathrm{C}$.

The diagrams show the results achieved on four independent, successively tested samples of the studied material. The figures show how the value of $50 \mathrm{~N}$ was crossed at the beginning of the measurements (for time $t=0 \mathrm{~s}$ ), that is, after the procedure of stretching the analysed samples of asphalt binders came to an end, which was caused by the inertia of the extension mechanism of the ductilometer. However, the phenomenon at hand does not affect the precision of the determinations, as in all analysed cases the maximum value of the tensile force remained in the range $(56 \pm 2)$ $\mathrm{N}$. It has been noted that in the case of binders modified with the natural Trinidad Epuré asphalt, the differences in the tensile force values from four different samples, compared to road bitumens and Gilsonite modified binders, are twice as high, with the variation from the average value in most cases amounting to maximum \pm 1 $\mathrm{N}$. This can be a consequence of the fact that the Trinidad Epuré additive consists almost in half $(45 \%$ of the additives' mass) of mineral parts (prevailingly, dust). As a result, the section structures of the tested samples taken from the same material may differ.

Figures 5 and 6 show interdependencies of the medium extension stress in the field of time occurring in the samples of the analysed asphalt binders. 


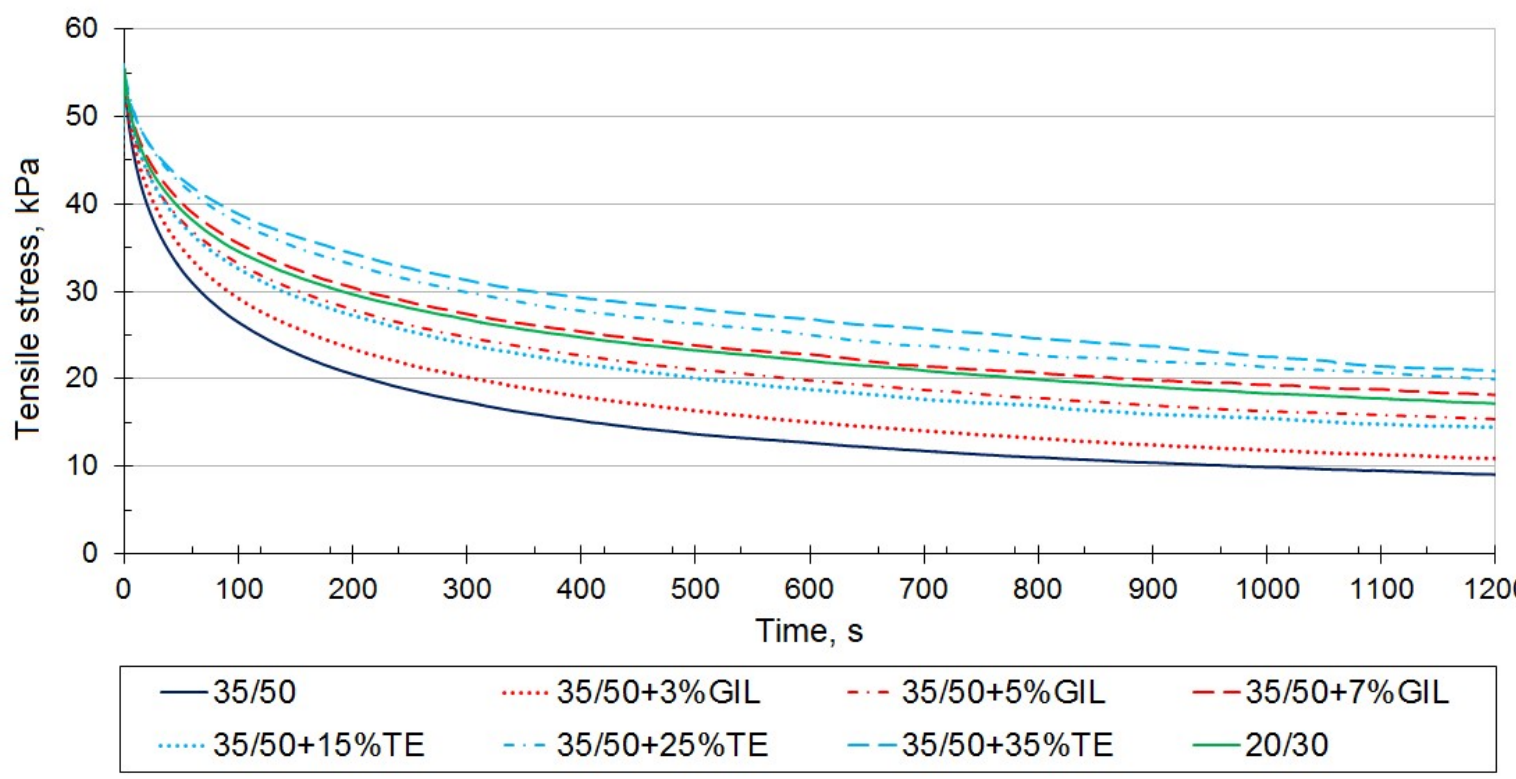

Fig. 5. Average values of tensile stress in the time domain in the conditions of constant strain of 20/30 and 35/50 penetration grade bitumens, as well as modified asphalt binders containing $35 / 50$ penetration grade bitumen at $-16^{\circ} \mathrm{C}$.

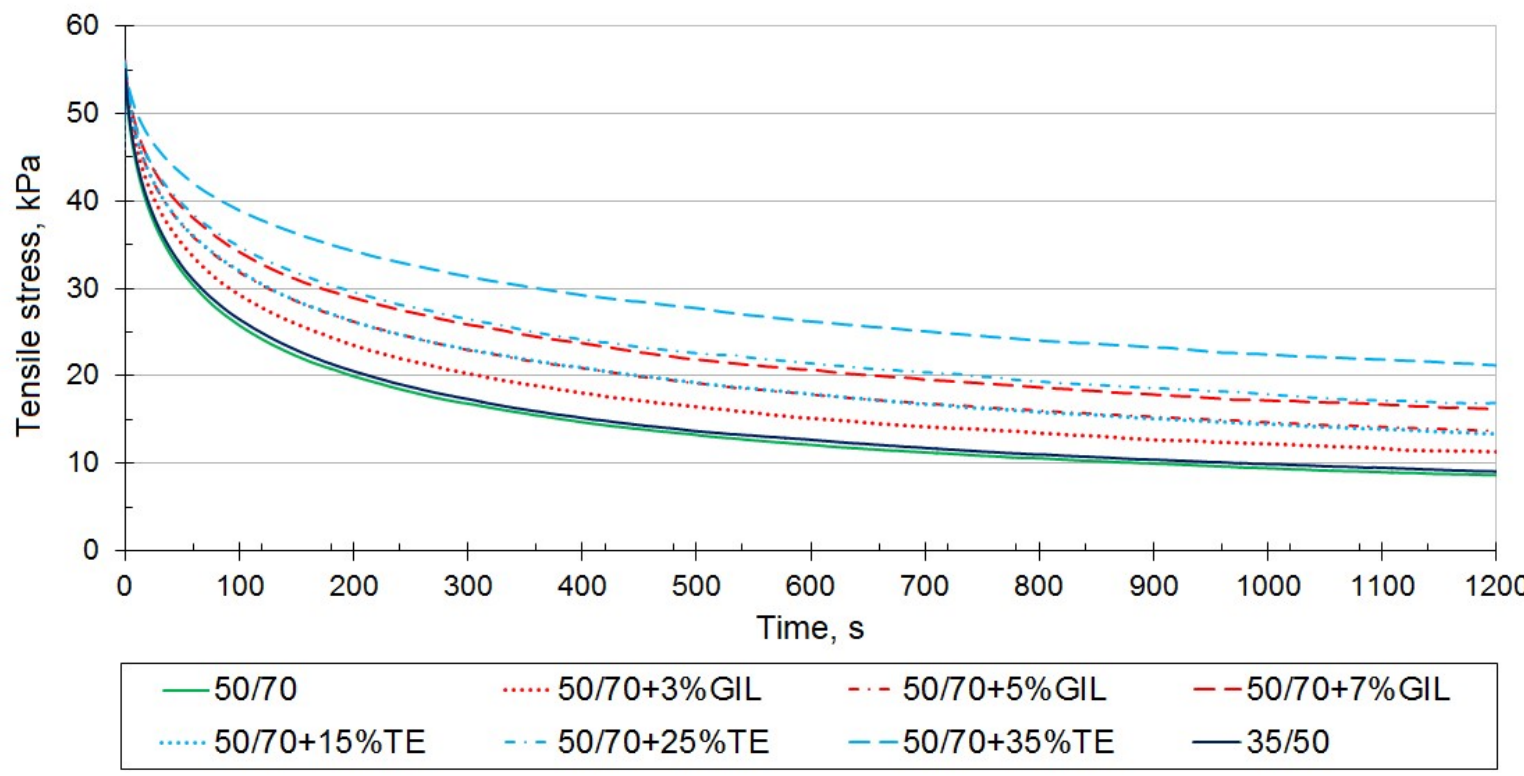

Fig. 6. Average values of tensile stress in the time domain in the condition of constant strain of $35 / 50$ and 50/70 penetration grade bitumens, as well as modified asphalt binders containing $50 / 70$ penetration grade bitumen at $-16^{\circ} \mathrm{C}$.

It has been observed that the harder the asphalt binder, (the lower penetration value at $25^{\circ} \mathrm{C}$ ), the slower relaxation takes place, and its intensity is also lower. Interestingly, despite comparable penetration values at $25^{\circ} \mathrm{C}$, characterising modified bitumens with particular additives of natural asphalts, Trinidad Epuré's relaxation ability is lower than in the case of Gilsonite modification. Most probably, this is connected with the high percentage of mineral parts in the Trinidad Epuré additive. The values of tensile stress calculated for the chosen time $t=60 \mathrm{~s}$ from the moment of producing in the sample the conditions of constant strain $(t=0 \mathrm{~s})$ were greater in the case of asphalt modified binders with the Trinidad Epuré additive by approximately $2 \mathrm{kPa}$, compared with their Gilsonitemodified counterparts, and by so much as $5 \mathrm{kPa}$ within the range of stress values in the time from $300 \mathrm{~s}$ to 1200 s. Some narrowly smaller differences in tensile stress values have been noted between asphalt binders containing the given natural asphalt additives when these were used to modify a very soft binder, that is the 50/70 penetration grade bitumen. The fact that no significant differences in relaxation ability have been observed for $35 / 50$ and 50/70 penetration grade road bitumens can be explained with their similar colloidal structure and oil content, which distinguishes them from 20/30 penetration grade road bitumen. Asphalt binders containing the Gilsonite or Trinidad Epuré additives are characterised by higher tensile stress value than the referential bitumens (subjected to modification) due to the stiffening properties of natural asphalts. 35/50 penetration grade bitumen, modified with the Gilsonite 
additive in the amount of 5\% or Trinidad Epure in the amount of $25 \%$, shows a similar penetration value at $25^{\circ} \mathrm{C}$ to the $20 / 30$ penetration grade bitumen. The $35 / 50+5 \%$ GIL modified asphalt binder shows a higher relaxation ability at $-16^{\circ} \mathrm{C}$ than the $20 / 30$ penetration grade bitumen and the $35 / 50+25 \%$ TE modified asphalt binder. All modified asphalt binders containing 50/70 penetration grade bitumen are characterised by a lower relaxation ability than the $35 / 50$ penetration grade bitumen.

\section{Discussion}

It has been observed that asphalt binders modified with natural asphalt Gilsonite and Trinidad Epuré additives are characterised by relaxation curves that are not as decreasing in the temperature of $-16^{\circ} \mathrm{C}$ as the referential bitumens (which were used as the basis for modifications), which can result in a higher susceptibility of the road pavement to cracking when modified asphalt binders in this way are applied, especially in high percentages of natural asphalt. A lower relaxation ability of modified asphalt binders containing the Trinidad Epuré additive in comparison with Gilsonite may be caused by a high mineral parts content in Trinidad Epuré (constituting up to $45 \%$ of its weight).

In the case of similar penetration values of modified asphalt binders at $25^{\circ} \mathrm{C}$ (maximum difference between penetration values equalling $\pm 2 \mathrm{~mm} / 10$ ), asphalt binders containing the Gilsonite additive show a higher relaxation ability rather than Trinidad Epuré. On the other hand, at comparable penetration at $25^{\circ} \mathrm{C}$, the $35 / 50$ penetration grade binder, modified with the Gilsonite additive in the amount of 5\%, shows a better relaxation ability than $20 / 30$ penetration grade road bitumen. The $35 / 50$ penetration grade road bitumen is, in turn, characterised by a better relaxation ability than all natural asphalt-modified binders.

It can be concluded that the applied original test method used to assess relaxation in the conditions of constant strain at low temperature can be applied for determining the influence of modifying bitumens with various additives on the variations in road bitumens properties. In order to better recognize the changes occurring in bitumens which are modified by natural asphalts, the authors of the paper plan to extend the scope of further research by using spectroscopes.

\section{Conclusions}

- Asphalt binders containing the Gilsonite additive show a higher relaxation ability than the ones containing Trinidad Epuré (at similar penetration values at $25^{\circ} \mathrm{C}$ )

- At similar penetration values, at $25^{\circ} \mathrm{C}$, road bitumens modified with the Gilsonite additive in the amount of $5 \%$ show a better relaxation ability than the 20/30 penetration grade road bitumen.
- The $35 / 50$ penetration grade road bitumen is characterised by a better relaxation ability than all studied natural asphalt-modified binders.

\section{References}

1. M. Pszczoła, Road and Bridges - Drogi i Mosty, 3, 76-110 (2006)

2. G. Airey, J. Grenfell, A. Apeagyei, A. Subhy, D. Lo Presti, Mech. Time Depend Mat., 20(3), 455-480 (2016)

3. M. Słowik, M. Bilski, Balt. J. Road Bridge Eng., 12(2), 71-81 (2017)

4. M. Marasteanu, A. Basu, Road Mater Pavement, 5(1), 121-131 (2004)

5. O. Andersson, Nature 211, (1966)

6. M. Cholewińska, M. Iwański, G. Mazurek, J. Road Bridge Eng., 13(1), 34-39 (2018)

7. Coufalik, O. Dasek, J. Kachtik, J. Kudrna, S. Stoklasek, International Journal on Pavement Engineering \& Asphalt Technology, 5(1), 66-81 (2015)

8. L. Wen-Long, Conference Materials: Conferences of International Conference on Computer Science and Engineering Technology, Hong Kong, May 3031 (2015)

9. M. Bilski, M. Słowik, M. Mielczarek, JCEEA, 6301-t2, 137-144 (2016)

10. N. Nciri, S. Song, N. Kim, N. Cho, J. Pet. Environ. Biotechnol., 5, 193 (2014)

11. T. Boden, B. Tripp (Salt Lake City. UT: Utah Geological Survey, 2012)

12. R. Charles, F. Grimaldi, W. Indian J. Eng., 18, 2940 (1996)

13. I. Widyatmoko, R. Elliott R , Constr. Build. Mater., 22, 239-249 (2008) 